\title{
Fiber optic distributed temperature sensing for the determination of the nocturnal atmospheric boundary layer height
}

\author{
C. A. Keller ${ }^{1}$, H. Huwald ${ }^{2}$, M. K. Vollmer ${ }^{1}$, A. Wenger ${ }^{1}$, M. Hill ${ }^{1}$, M. B. Parlange ${ }^{2}$, and S. Reimann ${ }^{1}$ \\ ${ }^{1}$ Empa, Swiss Federal Laboratories for Materials Science and Technology, Duebendorf, Switzerland \\ ${ }^{2}$ School of Architecture, Civil and Environmental Engineering, EPFL, Lausanne, Switzerland
}

Received: 1 April 2010 - Published in Atmos. Meas. Tech. Discuss.: 24 June 2010

Revised: 26 January 2011 - Accepted: 27 January 2011 - Published: 3 February 2011

\begin{abstract}
A new method for measuring air temperature profiles in the atmospheric boundary layer at high spatial and temporal resolution is presented. The measurements are based on Raman scattering distributed temperature sensing (DTS) with a fiber optic cable attached to a tethered balloon. These data were used to estimate the height of the stable nocturnal boundary layer. The experiment was successfully deployed during a two-day campaign in September 2009 , providing evidence that DTS is well suited for this atmospheric application. Observed stable temperature profiles exhibit an exponential shape confirming similarity concepts of the temperature inversion close to the surface. The atmospheric mixing height $(\mathrm{MH})$ was estimated to vary between $5 \mathrm{~m}$ and $50 \mathrm{~m}$ as a result of the nocturnal boundary layer evolution. This value is in good agreement with the $\mathrm{MH}$ derived from concurrent Radon-222 $\left({ }^{222} \mathrm{Rn}\right)$ measurements and in previous studies.
\end{abstract}

\section{Introduction}

Air pollutants emitted at the surface are mixed into the lowest layer of the atmosphere that, depending on meteorological conditions, varies largely in depth from a few meters to a few kilometers (Brutsaert, 1982; Stull, 1988). The atmospheric boundary layer height, hereafter referred to as mixing height $(\mathrm{MH})$, denotes the vertical extent of this layer making the $\mathrm{MH}$ a key parameter for describing the physical state of the lower troposphere. Vertical mixing within this layer is driven by turbulence that is either produced mechanically (shear production) or produced and destroyed by buoyancy. The atmospheric boundary layer is commonly classified as unstable, neutral or stable, depending on the thermal strat-

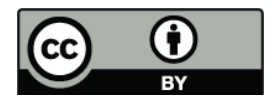

Correspondence to: C. A. Keller (christoph.keller@empa.ch) ification. For all conditions, various definitions of the $\mathrm{MH}$ exist, which is reflected in the numerous suggestions on how to measure or parameterize this quantity (Seibert et al., 2000, and references therein).

The stable boundary layer (SBL) normally develops during night time when solar warming stops and surface cooling due to a net negative long-wave radiation budget induces a stable stratification of the air. This process considerably weakens turbulent vertical mixing, leading to a $\mathrm{MH}$ in the range of only a few meters up to $500 \mathrm{~m}$ (e.g. Stull, 1988; Mahrt and Vickers, 2002; Pahlow et al., 2001; Salmond and McKendry, 2002; Cheng et al., 2005; Kumar et al.; Steinbacher et al., 2007). A shallow and persistent SBL over land surfaces typically develops after hot and dry summer days under low wind and clear sky conditions. Such conditions are of particular interest as they represent an excellent possibility to estimate the local flux of atmospheric trace gases (e.g. Conen et al., 2002; Buchmann et al., 2003; Steinbacher et al., 2007). Since the temperature profile reflects the balance between surface cooling and vertical mixing, highly resolved measurements of the evolution of this profile provide valuable information about the state of the SBL.

Radiosondes are the most commonly used means to provide high-resolution information on vertical profiles of meteorological parameters such as temperature, humidity and wind speed (e.g. Sempreviva and Gryning, 2000; Johansson and Bergstro, 2005; Basha and Ratnam, 2009). However, radio soundings are usually only taken at specific times, wherefore these data do not allow studying the short term evolution of the atmosphere. A continuous monitoring of the atmosphere is possible with remote sensing systems such as lidars (Eichinger et al., 1993; Pahlow et al., 2005) and RASSsodars (Nadeau et al., 2009). Unfortunately, these systems can be limited in vertical resolution which makes it difficult to accurately detect very low $\mathrm{MH}$, or they have other limitations due to eye safety or noise pollution (e.g. Clifford et al., 1994; Lammert and Boesenberg, 2005; Hennemuth

Published by Copernicus Publications on behalf of the European Geosciences Union. 
and Lammert, 2006; Emeis et al., 2008). An important tool for studying the boundary layer height has been measurements on tall towers and tethered balloons (e.g. Clarke, 1972; Haugen et al., 1971; Soilemes et al., 1993; Van Ulden and Wieringa, 1996; Schnitzhofer et al., 2009). While high spatial resolution can be achieved with a tall tower (although associated with high costs), it is impossible to obtain an instantaneous high resolution temperature profile from a tethered balloon system which typically carries only one sensor.

Raman scattering fiber optic distributed temperature sensing (DTS) has recently proven to be a powerful tool for accurately measuring ambient temperature at high temporal (1 min) and spatial $(1 \mathrm{~m})$ resolution over distances of several kilometers (Selker et al., 2006a,b; Tyler et al., 2009; Roth et al.). It is based on the inelastic scattering of photons (Raman effect) causing a temperature dependent intensity ratio between the amplitudes of the backscattered Stokes to antiStokes signals. Laser pulses travel within an optical fiber and the backscattered light reaches a detector where the intensity of the incident signals is evaluated. The exact position on the fiber of a backscattered signal is determined from the time of flight of a light pulse. The spatial resolution of a DTS system is hardware constraint and depends on the laser pulse length and frequency, and the detector analysis speed. The temporal resolution is basically user specified and depends on the noise level acceptance. A longer integration time reduces the noise level by means of a longer sampling and averaging period. For a more detailed description of the DTS system, the reader is referred to Selker et al. (2006a) who also give several examples of possible applications of DTS for temperature measurements in different environmental systems. To date, the use of DTS in environmental monitoring has been predominantly focused on hydrological applications (e.g. Selker et al., 2006b; Westhoff et al., 2007; Moffett et al., 2008; Tyler et al., 2008; Hoes et al., 2009; Vogt et al., 2010; Roth et al.), although its characteristics also perfectly meet the requirements for atmospheric sensing.

In this context, the Nocturnal Boundary Layer Balloon Experiment (NOBALEX) was carried out in September 2009 in a suburban area (Duebendorf, Switzerland) with the aim to test the ability of DTS for measuring the evolution of vertical temperature profiles within the stable boundary layer as well as to estimate fluxes of anthropogenic pollutants between the surface and the atmosphere.

This paper focuses on the DTS measurements conducted during the NOBALEX campaign, including a description of the experimental setup, a quality analysis, and the estimation of the nocturnal MH. Results are compared with an independent estimation of the MH based on measurements of Radon-222 ( $\left.{ }^{222} \mathrm{Rn}\right)$.

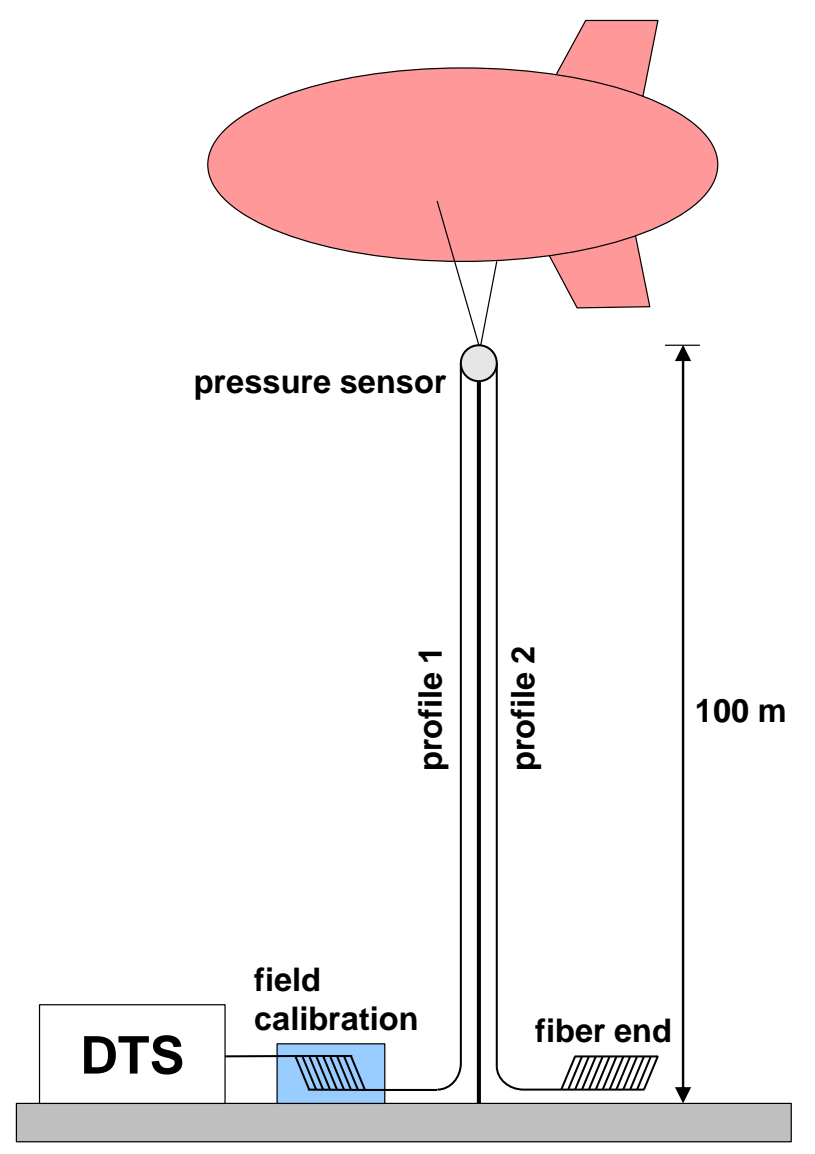

Fig. 1. Illustration of the experimental setup.

\section{Setup and experiments}

A schematic drawing of the experimental setup is shown in Fig. 1. A tethered balloon lifting system was used to vertically install a fiber optic cable (AFL mini-link, $900 \mu \mathrm{m}$ diameter, $0.7 \mathrm{gm}^{-1}$ ) in the lowest $100 \mathrm{~m}$ of the atmosphere. Connected to a DTS instrument (Agilent Technology, model $\mathrm{N} 4386 \mathrm{~A}$ ), the fiber cable was fixed along the $100 \mathrm{~m}$ cord of the tethered balloon $\left(4.25 \mathrm{~m}^{3}\right.$ helium; Wittich \& Visser, Rijswijk, The Netherlands). The fiber cable was measured in a single-ended configuration, with a $60 \mathrm{~m}$ lead section of the fiber cable coiled up in a thermally insulated water bath of an accurately known temperature (measured by several HOBO Tidbit temperature loggers with a resolution of $0.02{ }^{\circ} \mathrm{C}$ and an accuracy of $0.2^{\circ} \mathrm{C}$ ), allowing for an in-situ calibration of the DTS system. The next $200 \mathrm{~m}$ of the fiber string were looped up and down along the balloon cord. As a consequence, two temperature profiles could be measured simultaneously, enabling to check both the quality and consistency of the measurements as well as the spatial repeatability of the employed system. The last $350 \mathrm{~m}$ section of the fiber cable remained on the spool but was also measured to exclude signal perturbations (which are typically present 
near the fiber termination) from the two profiles of interest. The spatial resolution along the fiber of the DTS system in use was $1 \mathrm{~m}$.

The loss in optical intensity that weakens the backscattered signal increases with distance along the fiber and is specific for the fiber optical cable used. To quantify and correct for this effect, the cable was pre-calibrated in the lab prior to the experiments by measuring two different cable sections of $50 \mathrm{~m}$ each in a reference container (water bath) of known temperature. Note that inserting the far end cable section (after the downward profile) into the water bath as well would enable to derive the attenuation signal directly from the field experiment data. This slight modification of the setup would supersede the pre-calibration of the fiber and we recommend adding this desirable feature into future studies.

The integration time for the DTS measurements was set to $5 \mathrm{~min}$. This period is long enough to obtain a precision for temperature better than $0.5^{\circ} \mathrm{C}$ and short enough to account for the time scale of changes in the temperature profile. The response time of the plastic coated fiber optic cable to a sudden ambient air temperature change was observed to be well within the specified integration time. We therefore conclude that for night time conditions, the cable is in equilibrium with the ambient air and measurement errors due to long-wave radiative losses of the cable are expected to be negligible. This assumption does not necessarily hold for daytime measurements, when the influence of short-wave radiation on the radiative budget of the fiber becomes significant. Therefore, the application of a cable during daytime requires detailed investigation before using it under such conditions.

Averaging the two simultaneously measured temperature profiles allows distinguishing between measurement noise and real fluctuations. Results show that the two simultaneously measured sections (profiles) of a measurement (temperature trace) are highly correlated and it is concluded that temperature changes are well captured using an integration time of 5 min (see below).

Atmospheric pressure was measured with high frequency (every $8 \mathrm{~s}$ ) at approximately $1 \mathrm{~m}$ below the balloon using a P300-Baro pressure sensor (Pace Scientific Inc.). The pressure information can be used to derive the height above ground of the balloon. For moderate to high wind speed conditions, this procedure is more accurate than using the length of the cord since it is not affected by the wind drag of the balloon.

To additionally measure anthropogenic pollutants in the near-surface atmosphere, a $150 \mathrm{~m}$ Teflon tube was fixed to the balloon cord and air was drawn through the tube by a membrane pump for sampling and analysis at the ground. These results will be presented elsewhere.

All measurements were carried out at a station of the Swiss National Air Pollution Monitoring Network (NABEL) in Duebendorf $\left(47^{\circ} 24^{\prime} \mathrm{N}, 8^{\circ} 36^{\prime} \mathrm{E}, 433 \mathrm{~m}\right.$ above sea level), within a suburban area located about $10 \mathrm{~km}$ west of Zurich. All principal meteorological parameters and a suite of trace gases are continuously measured as part of the monitoring programme. To complement this data set and to obtain a second, independent estimate of the $\mathrm{MH}$, measurements of ${ }^{222} \mathrm{Rn}$ were carried out throughout the experimental period. Ambient air concentrations of ${ }^{222} \mathrm{Rn}$ were measured at $10 \mathrm{~m}$ above ground using a dual loop two-filter system (Zaharowski et al., 2004). In addition, an accumulation chamber in combination with an Alphaguard Radon detector monitor (SAPHYMO GmbH, Frankfurt a.M., Germany) as described in detail by Szegvary et al. (2007) was used to determine the local exhalation rate of ${ }^{222} \mathrm{Rn}$.

A first measurement campaign (8 September, 4 p.m. to 9 September, 9 a.m., 2009, UTC +1) was conducted with the goal to derive vertical profiles of greenhouse gases. Therefore, the balloon was repeatedly moved to discrete heights $(100 \mathrm{~m}, 80 \mathrm{~m}, 50 \mathrm{~m}, 35 \mathrm{~m}, 20 \mathrm{~m}, 10 \mathrm{~m}, 5 \mathrm{~m}, 2 \mathrm{~m})$ where it was kept for approximately 15 minutes before being shifted to the next level. This procedure resulted in several profiles of heights less than $100 \mathrm{~m}$. A second campaign (10 September,7 p.m. to 11 September, 9 a.m., 2009, UTC +1 ) was specifically dedicated to the acquisition of vertical temperature profiles of the near-surface atmosphere and the balloon was permanently kept at a height of $100 \mathrm{~m}$ above ground, providing a complete temperature record throughout the night.

\section{Data analysis and results}

Measurements were collected during two nights following warm days with daily temperature maxima of $25.1^{\circ} \mathrm{C}$ and $24.3^{\circ} \mathrm{C}$, respectively. By the early morning, surface air temperatures had decreased to $9.6{ }^{\circ} \mathrm{C}$ and $12.4{ }^{\circ} \mathrm{C}$ and wind speeds at the $10 \mathrm{~m}$ level never exceeded $1 \mathrm{~ms}^{-1}$ during the night. The balloon did not experience significant horizontal drag during the flights which implies that wind speed was weak within the entire $100 \mathrm{~m}$ slab. This is confirmed by the fact that balloon heights determined based on pressure measurements were very close to $100 \mathrm{~m}$ throughout the night. It is therefore reasonable to consider the cable distances to be representative for the balloon height and in the following all results are given with reference to the fiber cable length.

Mean net radiation at the surface between 7 p.m. to 7 a.m. was $-71.0 \mathrm{Wm}^{-2}$ in the first night and $-53.2 \mathrm{Wm}^{-2}$ in the second, indicating strong surface cooling. While the first night was clear, light clouds appeared in the second half of the second night explaining the less pronounced cooling.

\subsection{Example trace}

An exemplary measurement from the DTS instrument is shown in Fig. 2. The upper panel shows the temperature record along the first $350 \mathrm{~m}$ of the fiber cable measured during a 5 min integration period, the lower panel depicts the intensity loss (in $\mathrm{dB}$ ) which occurred along the same 


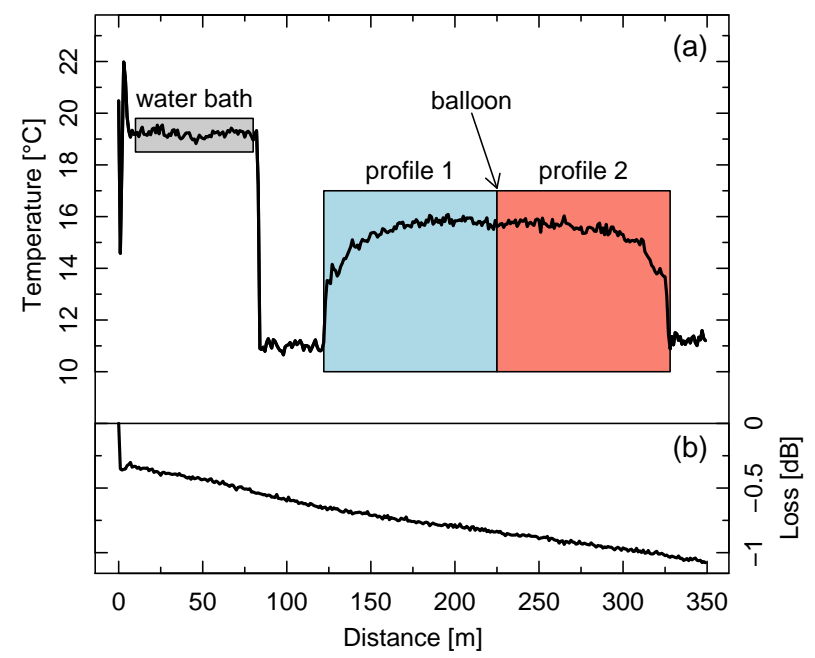

Fig. 2. DTS record of 11 September, 02:20 a.m. along the first $350 \mathrm{~m}$ of the fiber cable. (a) Temperature measurements in ${ }^{\circ} \mathrm{C}$, the shaded areas show the location of the calibration section (water bath) and the upward and downward atmospheric profile fiber cable sections. (b) Loss of signal intensity (dB).

distance. The signal intensity decreases along the cable at a constant rate of approximately $3 \mathrm{dBkm}^{-1}$. The absence of noticeable steps in the loss trace indicates that the measurement is not subject to local inhomogeneities, perturbations or irregularities along the cable (the steep drop in intensity at the beginning of the sensor cable is a result of the fiber connection to the DTS instrument).

The mean temperature of the in-situ calibration section (10-70 m) was $19.2^{\circ} \mathrm{C}$ during the experiment, only $0.6^{\circ} \mathrm{C}$ lower than the uniform temperature of $19.8^{\circ} \mathrm{C}$ of the water bath. This final offset correction was applied to all DTS temperature measurements.

The upward and downward segment (profile 1 and 2) of the vertical temperature profiles of the atmosphere were derived using the information where the balloon was fixed to the fiber string and at which altitude the balloon resided. The two profiles coincide well and have a correlation coefficient $R^{2}$ equal to 0.98 and a root mean square error (RMSE) of $0.44^{\circ} \mathrm{C}$. These values demonstrate that the system calibration procedure resulted in the determination of a valid set of parameters for the specific optical fiber used during the experiments.

Indeed, offset-corrected DTS temperature measurements are corroborated when compared to conventional temperature measurements with a ventilated thermohygrometer (Thygan VTP, Meteolabor, Switzerland) observed at the NABEL station, as shown in Fig. 3 (comparison of data at the same height above ground). Except for a short period in the morning (around 4 a.m.), DTS measurements closely follow the NABEL measurements and no significant differences between the two DTS segments are observed.

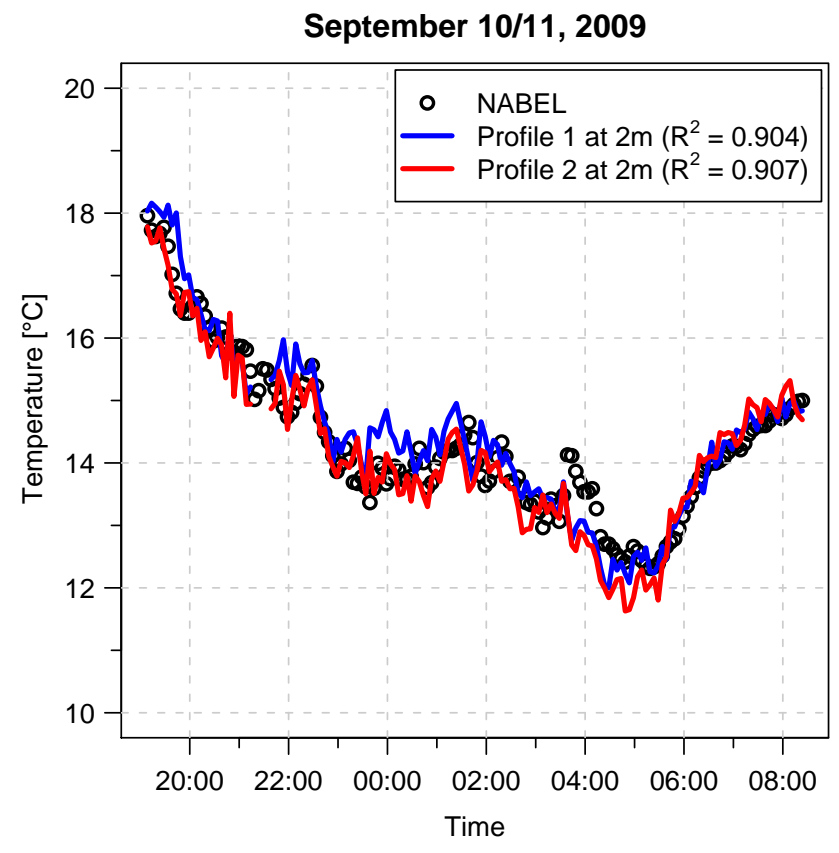

Fig. 3. Comparison of DTS temperatures measured $2 \mathrm{~m}$ above ground and air temperature measurements from the collocated NABEL network station (cf. Fig. 1 for definition of profiles). Correlations between DTS measurements and NABEL data are given in the legend.

\subsection{Temperature profiles and MH estimation}

The evolution of the potential temperature $\Theta$ during the second campaign is shown in Fig. 4a. As observed in the measurements of campaign 1 , the potential temperature was almost constant throughout the entire layer before sunset at about $06: 50$ p.m., indicating a well mixed boundary layer during this time. With sunset, the air near the surface started to cool and an inversion developed. Since this cooling is induced by the net heat loss of the ground due to strong radiative cooling, the air next to the surface experiences the strongest temperature decrease. The stable atmospheric stratification was eroded shortly after sunrise when the surface quickly warmed up again and latent and sensible heat was transferred to the atmosphere leading to increased convection, turbulence and mixing.

Figure $4 b$ shows a representative nocturnal profile of $\Theta$. This profile can be described with an exponential model (Stull, 1988)

$\Delta \Theta(z)=\Delta \Theta_{s} \cdot e^{-z / H}$

where $\Delta \Theta_{s}$ is the potential temperature difference between the non-disturbed air aloft and the surface (in ${ }^{\circ} \mathrm{C}$ ), $z$ is the height (in $\mathrm{m}$ ) and $H$ is the e-folding depth in $\mathrm{m}$. $H$ denotes the depth of a rectangle with abscissa $\Delta \Theta_{s}$ which covers the same area as below the exponential curve and is therefore often referred to as the mixing height (Stull, 1988). 

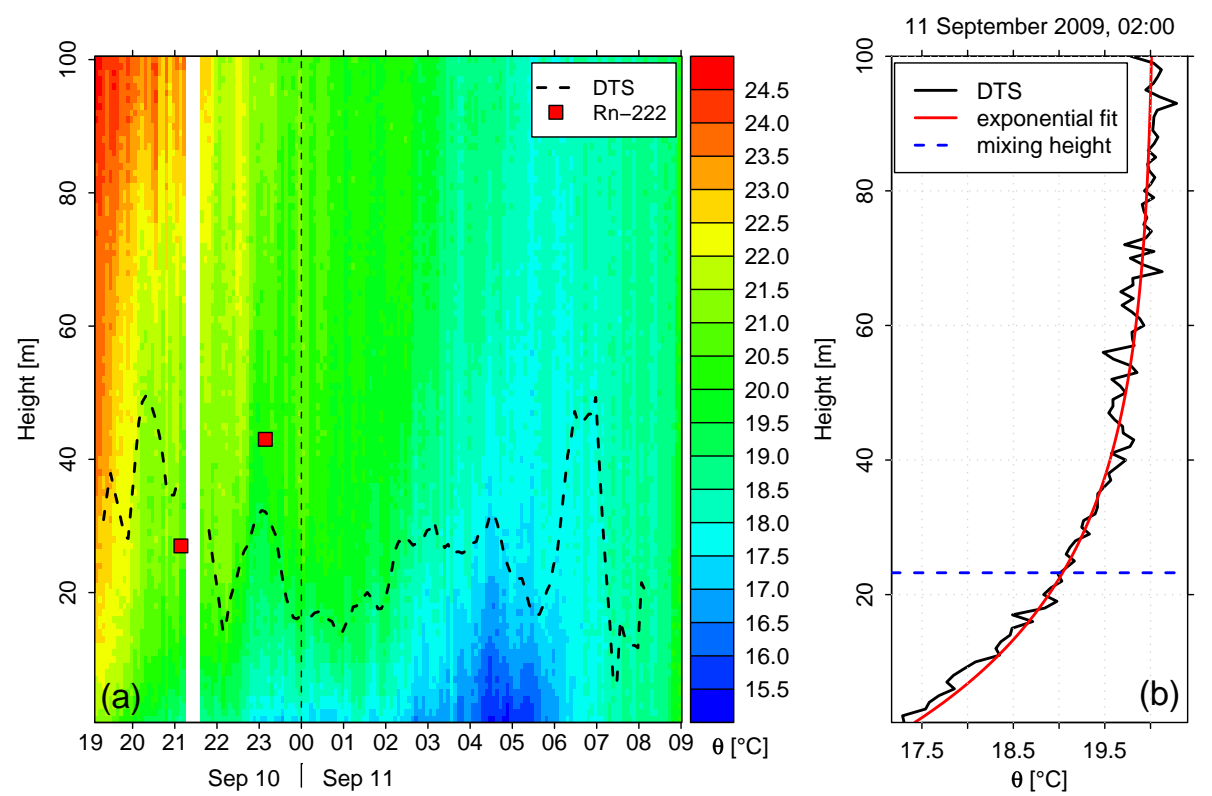

Fig. 4. (a) Evolution of potential temperature $\Theta$ during campaign 2 (10 September 7 p.m.-11 September, 9 a.m.). The bold dashed line and the red squares denote the mixing heights as determined from exponential profile fits and ${ }^{222} \mathrm{Rn}$ measurements, respectively. The white vertical band is a period of missing data; (b) Example of a DTS measurement profile for 11 September, 2 a.m. (black) and the corresponding best fit of an exponential curve (red). Mixing height $H$ is shown in blue.

For every temperature profile during stable atmospheric conditions, a minimum RMSE fit between observed and theoretical profile (Eq. 1) was calculated which provided the MH for each time. This MH varied between $5 \mathrm{~m}$ and $50 \mathrm{~m}$ during night 2 (Fig. 4a, bold dashed line) and between $15 \mathrm{~m}$ and $45 \mathrm{~m}$ during night 1 (no figure shown). These values are similar to the MH previously estimated for the same site under similar meteorological conditions (Buchmann et al., 2003; Steinbacher et al., 2007).

\subsection{Comparison with MH estimated from Radon-222 measurements}

Radioactive ${ }^{222} \mathrm{Rn}$ has a precisely known lifetime of 5.5 days and is released from soils with relatively small spatial and temporal variability, wherefore it is often used as tracer for atmospheric dilution (e.g. Biraud et al., 2000; Schmidt et al., 2001; Conen et al., 2002; Zaharowski et al., 2004). Relating the observed concentration increase between time $t_{1}$ and $t_{2}$ to the local exhalation rate $F_{\mathrm{Rn} 222}\left(\right.$ in $\mathrm{Bqm}^{-2} \mathrm{~h}^{-1}$ ), the $\mathrm{MH}$ can be estimated by (Sesana et al., 2003)

$\mathrm{MH}=\frac{F_{\mathrm{Rn} 222}\left(1-e^{-\lambda \Delta t}\right)}{\lambda\left(C_{\mathrm{Rn} 222}\left(t_{2}\right)-C_{\mathrm{Rn} 222}\left(t_{1}\right) e^{-\lambda \Delta t}\right)}$

with $\lambda$ being the radioactive decay constant of ${ }^{222} \mathrm{Rn}(7.55$. $10^{-3} \mathrm{~h}^{-1}$ ), and $C_{\mathrm{Rn} 222}(t)$ the measured ${ }^{222} \mathrm{Rn}$ concentration at time $t$. From 7 September to 12 September, measured ${ }^{222} \mathrm{Rn}$ concentrations at Duebendorf showed a distinct diurnal cycle with values on the order of $5 \mathrm{Bqm}^{-3}$ during the day but rising to more than $20 \mathrm{Bqm}^{-3}$ during night. Mean exhalation rates amounted to $65 \mathrm{Bqm}^{-2} \mathrm{~h}^{-1}$, which is in good agreement with the value of $67.9 \mathrm{Bqm}^{-2} \mathrm{~h}^{-1}$ approximated from gamma dose rate data by Szegvary et al. (2007) for this region. Applying Eq. (2) to the ${ }^{222} \mathrm{Rn}$ measurements during the two campaigns (using $\Delta t=2 \mathrm{~h}$ ), a MH varying between $15 \mathrm{~m}$ and $50 \mathrm{~m}$ is derived (see red squares in Fig. 4a).

${ }^{222} \mathrm{Rn}$ concentrations decreased in the second half of campaign 2, wherefore no $\mathrm{MH}$ could be estimated and indicating that residual air was mixed into the SBL during this period. This process is not reflected by the DTS measurements, showing that caution is needed when comparing the MH derived from the ${ }^{222} \mathrm{Rn}$ accumulation with the $\mathrm{MH}$ estimated from surface cooling since the time scales and the underlying physical principles may differ. While the ${ }^{222} \mathrm{Rn}$ method is representative for how effectively air has been mixed within the considered time span of $2 \mathrm{~h}$, the temperature profile depicted by the DTS system reflects the current state of the lower atmosphere and its thermal stability. Nevertheless, where a direct comparison is possible, the $\mathrm{MH}$ estimated by the two methods lie within a factor of 1.5. This result indicates that under stable conditions, the evolution of the potential temperature profile is a good measure for atmospheric mixing. 


\section{Conclusions}

Raman scattering fiber optic distributed temperature sensing (DTS) in combination with a tethered balloon was successfully applied to measure the evolution of high resolution vertical temperature profiles within the atmospheric boundary layer. Results from a series of field experiments demonstrate that DTS is very well suited for atmospheric applications. The measurement technique and experimental setup presented in this study constitute an important extension of past DTS applications, typically in the area of hydrological monitoring and geo-engineering. As a result of its relatively easy handling, DTS constitutes an interesting and promising alternative for measuring atmospheric temperature profiles with high spatial and temporal resolution when compared to conventional techniques. It may also be used as a reference for in-situ validation of other sampling techniques such as atmospheric boundary layer lidars.

Measurements were carried out during two clear nights in September 2009 in the presence of relatively strong temperature inversions. Most of the temperature profiles measured during this study closely match an exponential model, showing the evolution of a strong inversion in the boundary layer during the observational periods. The $\mathrm{MH}$ derived from the temperature profiles varied between $5 \mathrm{~m}$ and $50 \mathrm{~m}$. This value is similar to those estimated in previous studies and deviates less than $50 \%$ from the $\mathrm{MH}$ derived from ${ }^{222} \mathrm{Rn}$ measurements at the same site using a mass balance approach. The relatively high sampling frequency of the DTS measurements allows the estimation of a MH with a temporal resolution of only $5 \mathrm{~min}$.

Up to now, the method presented in this study is restricted to low wind conditions, since the tethered balloon system suffers from strong wind drag otherwise. For using the fiber optic DTS system continuously and under more challenging weather conditions, installing it on a tall tower or mast might be an interesting alternative.

Acknowledgements. We highly acknowledge the cooperation of F. Conen in conducting and calibrating the Rn-222 measurements. W. Eugster contributed with both technical support and scientific discussions. We are grateful to M. Steinbacher, D. Brunner and S. Henne for helpful discussions. The Swiss National Air Pollution Monitoring Network (NABEL) is run by Empa in joint collaboration with the Swiss Federal Office for the Environment. This project was funded by the Swiss National Science Foundation (project no. 200021-117753, 200020-125092/1 and 200021120238). The long review period was only due to editorial issues and was unrelated to the content of the manuscript.

Edited by: T. Wagner

\section{References}

Basha, G. and Ratnam, M. V.: Identification of atmospheric boundary layer height over a tropical station using high-resolution radiosonde refractivity profiles: Comparison with GPS radio occultation measurements, J. Geophys. Res., 114, D16101, doi: 10.1029/2008JD011692, 2009.

Biraud, S., Ciais, P., Ramonet, M., Simmonds, P., Kazan, V., Monfray, P., O’Doherty, S., Spain, T. G., and Jennings, S. G.: European greenhouse gas emissions estimated from continuous atmospheric measurements and radon 222 at Mace Head, Ireland, J. Geophys. Res., 105(D1), 1351-1366, doi:10.1029/ 1999JD900821, 2000.

Brutsaert, W.: Evaporation into the Atmosphere, Kluwer Academic Publishers, Dordrecht/Boston/Lancester, 1982.

Buchmann, B., Stemmler, K., and Reimann, S.: Regional emissions of anthropogenic halocarbons derived from continuous measurements of ambient air in Switzerland, Chimia, 57, 522-528, 2003.

Cheng, Y., Parlange, M. B., and Brutsaert, W.: Pathology of MoninObukhov similarity in the stable boundary layer, J. Geophys. Res-Atmos., 110, D06101, doi:10.1029/2004JD004923, 2005.

Clarke, R. H.: Observational studies in the atmospheric boundary layer, Q. J. Roy. Meteor. Soc., 98, 231-235, doi:10.1002/ qj.49709841525, 1972.

Clifford, S. F., Kaimal, J. C., Lataitis, R. J., and Strauch, R. G.: Ground-based remote profiling in atmospheric studies: an overview, Proceedings of the IEEE, 82(3), 313-355, doi:10. 1109/5.272138, 1994.

Conen, F., Neftel, A., Schmid, M., and Lehmann, B. E.: $\mathrm{N}_{2} \mathrm{O} /{ }^{222} \mathrm{Rn}$ - soil flux calibration in the stable nocturnal surface layer, Geophys. Res. Lett., 29(2), doi:10.1029/2001GL013429, 2002.

Eichinger, W. E., Cooper, D. I., Parlange, M., and Katul, G.: The application of a scanning, water raman-lidar as a probe of the atmospheric boundary layer, IEEE. T. Geosci. Remote, 31(1), 7079, 1993.

Emeis, S., Schafer, K., and Munkel, C.: Surface-based remote sensing of the mixing layer height - a review, Meteorol. Z., 17(5), 621-630, doi:10.1127/0941-2948/2008/0312, 2008.

Haugen, D. A., Kaimal, J. C., and Bradley, E. F.: An experimental study of Reynold stress and heat flux in the atmospheric surface layer, Q. J. Roy. Meteor. Soc., 97, 168-180, doi:10.1002/qj. 49709741204, 1971.

Hennemuth, B. and Lammert, A.: Determination of the atmospheric boundary layer height from radiosonde and lidar backscatter, Bound-Lay. Meteorol., 120, 181-200, doi:10.1007/ s10546-005-9035-3, 2006.

Hoes, O. A. C., Luxemburg, W. M. J., Westhof, M. C., van de Giesen, N. C., and Selker, J.: Identifying seepage in ditches and canals in Polders in the Netherlands by distributed temperature sensing, Lowland Technology International, 11(2), 21-26, 2009.

Johansson, C. and Bergstro, H.: An auxiliary tool to determine the height of the boundary layer, Bound-Lay. Meteorol., 115, 423432, doi:10.1007/s10546-004-1424-5, 2005.

Kumar, V., Kleissl, J., Meneveau, C., and Parlange, M. B.: Largeeddy simulation of a diurnal cycle of the atmospheric boundary layer: Atmospheric stability and scaling issues, Water Resour. Res., 42, W06D09, doi:10.1029/2005WR004651, 2006.

Lammert, A. and Boesenberg, J.: Determination of the convective boundary layer height with laser remote sensing, BoundLay. Meteorol., 119, 159-170, doi:10.1007/s10546-005-9020-x, 
2005.

Mahrt, L. and Vickers, D.: Contrasting vertical structures of nocturnal boundary layers, Bound-Lay. Meteorol., 105, 351-363, doi: 10.1023/A:1019964720989, 2002.

Moffett, K. B., Tyler, S. W., Torgersen, T., Menon, M., Selker, J. S., and Gorelick, S. M.: Processes controlling the thermal regime of saltmarsh channel beds, Environ. Sci. Technol., 42(3), 671-676, doi:10.1021/es071309m, 2008.

Nadeau, D. F., Brutsaert, W., Parlange, M. B., Bou-Zeid, E., Barrenetxea, G., Couach, O., Boldi, M. O., Selker, J. S., and Vetterli, M.: Estimation of urban sensible heat flux using a dense wireless network of observations, Environ. Fluid Mech., 9(6), 635-653, doi:10.1007/s10652-009-9150-7, 2009.

Pahlow, M., Parlange, M. B., and Porte-Agel, F.: On Monin-Obukhov similarity in the stable atmospheric boudary layer, Bound-Lay. Meteorol., 99, 225-248, doi:10.1023/A: 1018909000098, 2001.

Pahlow, M., Kleissl, J., Parlange, M. B.: Atmospheric boundarylayer structure observed during a haze event due to forestfire smoke, Bound-Lay. Meteorol., 114, 53-70, doi:10.1007/ s10546-004-6350-z, 2005.

Roth, T. R., Westhoff, M. C., Huwald, H., Huff, J. A., Rubin, J. F., Barrenetxea, G., Vetterli, M., Parriaux, A., Selker, J. S., and Parlange, M. B.: Stream temperature response to three Riparian vegetation scenarios by use of a distributed temperature validated model, Environ. Sci. Technol., 44(6), 2072-2078, doi:10.1021/ es902654f, 2010.

Salmond, J. A. and McKendry, I. G.: Secondary ozone maxima in a very stable nocturnal boundary layer: observations from the Lower Fraser Valley BC, Atmos. Environ., 36, 5771-5782, doi: 10.1016/S1352-2310(02)00698-2, 2002.

Schmidt, M., Glatzel-Mattheier, H., Sartorius, H., Worthy, D. E., and Levin, I.: Western European $\mathrm{N}_{2} \mathrm{O}$ emissions: A top-down approach based on atmospheric observations, J. Geophys. Res., 106, 5507-5516, 2001.

Schnitzhofer, R., Wisthaler, A., and Hansel, A.: Real-time profiling of organic trace gases in the planetary boundary layer by PTRMS using a tethered balloon, Atmos. Meas. Tech., 2, 773-777, doi:10.5194/amt-2-773-2009, 2009.

Seibert, P., Beyrich, F., Gryning, S.-E., Joffre, S., Rasmussen, A., and Tercier, P.: Review and intercomparison of operational methods for the determination of the mixing height, Atmos. Environ., 34, 1001-1027, doi:10.1016/S1352-2310(99)00349-0, 2000.

Selker, J. S., Thevenaz, L., Huwald, H., Mallet, A., Luxemburg, W., van de Giesen, N., Stejskal, M., Zeman, J., Westhoff, M., and Parlange, M. B.: Distributed fiber-optic temperature sensing for hydrological systems, Water Resour. Res., 42, W12202, doi: 10.1029/2006WR005326, 2006a.

Selker, J., van de Giesen, N., Westhoff, M., Luxemburg, W., and Parlange, M. B.: Fiber optics opens window on stream dynamics, Geophys. Res. Lett., 33, L24401, doi:10.1029/2006GL027979, $2006 b$.
Sempreviva, A. M. and Gryning, S.-E.: Mixing height over water and its role on the correlation between temperature and humidity fluctuations in the unstable surface layer, Bound-Lay. Meteorol., 97, 273-291, doi:10.1023/A:1002749729856, 2000.

Sesana, L., Caprioli, E., and Marcazzan, G. M.: Long period study of outdoor radon concentration in Milan and correlation between its temporal variations and dispersion properties of atmosphere, J. Environ. Radioactiv., 65(2), 147-160, doi:10.1016/ S0265-931X(02)00093-0, 2003.

Soilemes, A., Helmis, C. G., Papageorgas, P., and Asimakopoulos, D. N.: A tethered balloon profiler system, Meas. Sci. Technol., 4, 1163-1168, 1993.

Steinbacher, M., Fischer, A., Vollmer, M. K., Buchmann, B., Reimann, S., and Hueglin, C.: Perennial observations of molecular hydrogen $\left(\mathrm{H}_{2}\right)$ at a suburban site in Switzerland, Atmos. Environ., 41, 2111-2124, doi:10.1016/j.atmosenv.2006.10.075, 2007.

Stull, R. B.: An Introduction to Boundary Layer Meteorology, Kluwer Academic Publishers, Dordrecht, 1988.

Szegvary, T., Leuenberger, M. C., and Conen, F.: Predicting terrestrial ${ }^{222} \mathrm{Rn}$ flux using gamma dose rate as a proxy, Atmos. Chem. Phys., 7, 2789-2795, doi:10.5194/acp-7-2789-2007, 2007

Tyler, S. W., Burak, S. A., McNamara, J. P., Lamontagne, A., Selker, J. S., and Dozier, J.: Spatially distributed temperatures at the base of two mountain snowpacks measured with fiber-optic sensors, J. Glaciol., 54, 673-679, doi:10.3189/ $002214308786570827,2008$.

Tyler, S. W., Selker, J. S., Hausner, M. B., Hatch, C. E., Torgersen, T., Thodal, C. E., and Schladow, S. G.: Environmental temperature sensing using Raman spectra DTS fiber-optic methods, Water Resour. Res., 45, W00D23, doi:10.1029/2008WR007052, 2009.

Van Ulden, A. P. and Wieringa, J.: Atmospheric boundary layer research at Cabauw, Bound-Lay. Meteorol., 78, 39-69, doi:10. 1007/BF00122486, 1996.

Vogt, T., Schneider, P., Hahn-Woernle, L., and Cirpka, O. A.: Estimation of seepage rates in a losing stream by means of fiberoptic high-resolution vertical temperature profiling, J. Hydrol., 380, 154-164, doi:10.1016/j.jhydrol.2009.10.033, 2010.

Westhoff, M. C., Savenije, H. H. G., Luxemburg, W. M. J ., Stelling, G. S., van de Giesen, N. C., Selker, J. S., Pfister, L., and Uhlenbrook, S.: A distributed stream temperature model using high resolution temperature observations, Hydrol. Earth Syst. Sci., 11, 1469-1480, doi:10.5194/hess-11-1469-2007, 2007.

Zaharowski, W., Chambers, S. D., and Henderson-Sellers, A.: Ground based Radon-222 observations and their application to atmospheric studies, J. Environ. Radioactiv., 76, 3-33, doi: 10.1016/j.jenvrad.2004.03.033, 2004. 